\title{
DISTRIBUIÇÃO DE AÇÕES HORIZONTAIS EM EDIFÍCIOS DE ALVENARIA ES- TRUTURAL - COMPARAÇÃO ENTRE MÉTODOS DE PAREDES ISOLADAS E DE ASSOCIAÇÃO PLANA dE PAINÉIS
}

\author{
W. B. Vieira ${ }^{1}$, R. C. S. S. Alvarenga ${ }^{1}$, G. S. Veríssimo ${ }^{1}$ \\ ${ }^{1}$ Departamento de Engenharia Civil, Universidade Federal de Viçosa, Brasil. \\ (washington.vieira@ufv.br)
}

Resumo. Em edifícios de alvenaria estrutural constituídos de sistemas de contraventamentos simétricos e ações horizontais atuantes na direção da simetria, a distribuição destas ações entre os painéis de contraventamento pode ser realizada utilizando-se diferentes métodos, tais como o Método de Paredes Isoladas e o Método da Associação Plana de Painéis. O Método das Paredes Isoladas considera as paredes trabalhando isoladamente, separadas por aberturas (portas e janelas) e engastadas na base e livres na outra extremidade. Neste caso, considera-se que os deslocamentos horizontais ao nível das lajes em cada pavimento são iguais, pelo fato de existirem lajes de concreto que são consideradas como diafragmas rígidos. No Método da Associação Plana de Painéis, os painéis com abertura serão considerados como pórticos e os painéis sem abertura como paredes, formando no conjunto um pórtico plano. Pode-se considerar simultaneamente metade dos elementos de contraventamento paralelos à direção da ação horizontal, submetidos à metade desta ação, sendo ligados por elementos biarticulados que simulam a existência da laje. Neste trabalho é apresentada uma comparação dos esforços solicitantes devidos às ações horizontais aplicadas em um edifício em alvenaria estrutural, obtidos por meio do Método de Paredes Isoladas e do Método de Associação Plana de Painéis. Para a obtenção das solicitações no Método de Associação Plana de Painéis foi realizada análise elástica linear no software SAP 2000. Os resultados obtidos indicam que o Método da Associação Plana de Painéis simula melhor o comportamento da estrutura por considerar a distribuição de esforços de forma mais realística que o Método das Paredes Isoladas. Além disso, os resultados mostraram que o Método da Associação Plana de Painéis leva a um dimensionamento mais econômico.

Palavras chave: Alvenaria estrutural, Ações horizontais, Painéis de contraventamento. 


\section{INTRODUÇÃO}

\subsection{Generalidades}

Em relação às ações horizontais aplicadas, um sistema estrutural pode ser dividido em dois subsistemas, a saber, subsistema de contraventamento e subsistema contraventado. $\mathrm{O}$ subsistema de contraventamento consiste nos elementos estruturais que têm a função de absorver as ações horizontais e levá-las à fundação do edifício ([5]).

Em edifícios de alvenaria estrutural, o subsistema de contraventamento é formado pelas paredes cujos planos estejam na mesma direção da ação horizontal aplicada à estrutura, podendo-se considerar também um comprimento de abas de até seis vezes a largura dos blocos da parede, segundo [2]. A distribuição das ações nas paredes de alvenaria, quando existe simetria no subsistema de contraventamento, pode ser feita, utilizando, dentre outros métodos, o de Paredes Isoladas e o de Paredes com Aberturas, cujas descrições são apresentadas nos itens a seguir.

\subsection{Método de Paredes Isoladas}

No Método de Paredes Isoladas, considera-se que cada abertura - porta ou janela seja um delimitador das paredes, e, cada parede comporta-se como uma viga engastada na base e livre na outra extremidade, com as ações horizontais aplicadas ao nível de cada pavimento. Neste caso, considera-se que os deslocamentos horizontais ao nível das lajes em cada pavimento são iguais, pelo fato de existirem lajes de concreto que são consideradas como diafragmas rígidos.

As ações aplicadas em cada parede são proporcionais à sua rigidez. A força aplicada no pavimento $j$ da parede $i$ é dada pela expressão:

$$
\begin{gathered}
F_{i j}=F_{j} \cdot R_{i} . \\
R_{i}=\frac{I_{i}}{\sum I} .
\end{gathered}
$$

onde:

$F_{j}$ é a força total no pavimento $j$;

$R_{i}$ é a rigidez relativa da parede $i$;

$I_{i}$ é a inércia da parede $i$.

\subsection{Método de Paredes com Aberturas - Associação Plana de Painéis}

No Método de Paredes com Aberturas, os painéis sem aberturas são representados como paredes isoladas. Já os painéis com a presença de aberturas são representados como pórticos como pode ser visto na Figura 1a e na Figura 1 b. 
A seção transversal dos elementos verticais do pórtico é tomada da extremidade da parede à borda da abertura, considerando-se as abas, e com espessura igual à largura dos blocos.

Os elementos horizontais, chamados lintéis, são divididos em trechos rígidos e trechos flexíveis. Os trechos rígidos têm a altura da seção transversal equivalente ao pé direito estrutural e os trechos flexíveis têm altura $h_{v}$ apresentada na Figura 1b. Ambos os trechos têm largura igual à largura dos blocos.

Segundo recomendações de [3], o comprimento dos trechos flexíveis dos lintéis deve ser tomado como sendo a largura das aberturas somada a um comprimento $h_{v} / 2$ de cada lado (Figura 1c). Outra sugestão encontrada na literatura é considerar que o comprimento flexível dos lintéis seja apenas a largura das aberturas ([5]), como mostra a Figura 1d.

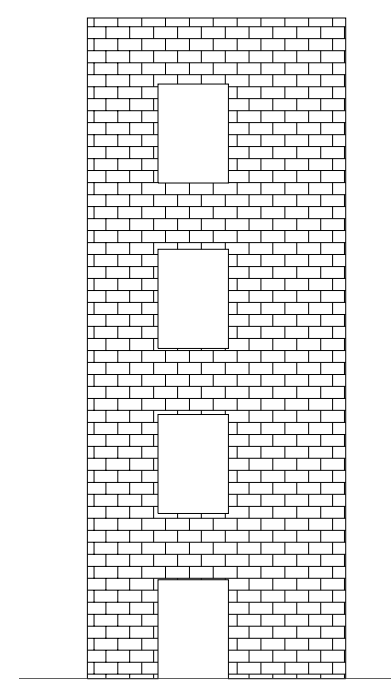

(a)

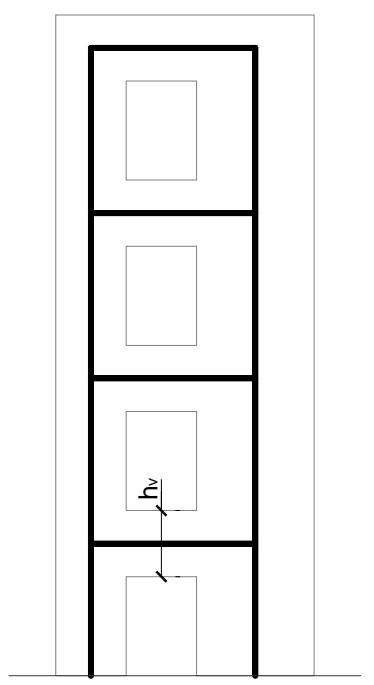

(b)

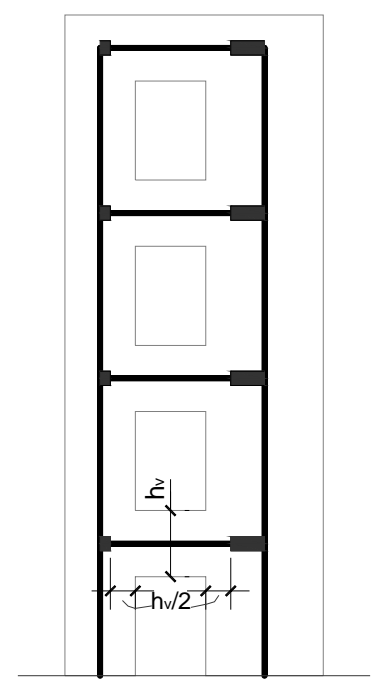

(c)

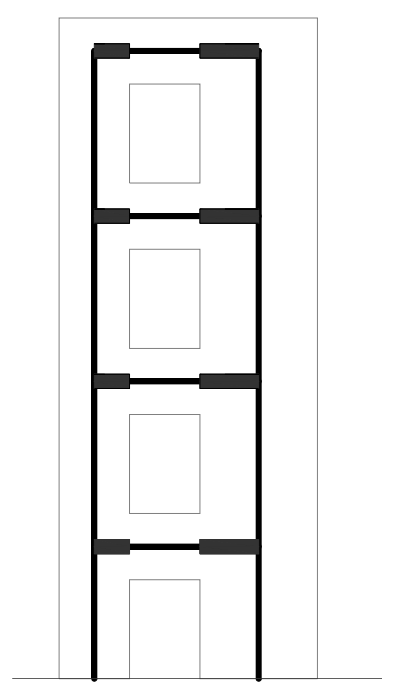

(d)

Figura 1. Método de Associação Plana de Painéis: (a) parede de alvenaria com aberturas; (b) representação da parede como pórtico; (c) trechos rígidos conforme [3]; e (d) trechos rígidos conforme [5].

Para se proceder à análise, realiza-se uma associação plana em série dos painéis ligados entre si por elementos biarticulados que simulam a existência da laje. Uma vez que esse método é aplicável aos sistemas de contraventamento simétricos, pode-se utilizar na análise a metade dos painéis submetidos à metade das ações horizontais.

\section{OBJETIVO}

O objetivo deste trabalho é efetuar uma análise comparativa entre os métodos de Paredes Isoladas e de Associação Plana de Painéis para distribuição das ações horizontais em edifícios de alvenaria estrutural.

As ações horizontais atuantes em um edifício usual de alvenaria estrutural são basicamente aquelas devidas ao vento e ao desaprumo. Uma vez que neste trabalho admite-se 
o comportamento linear e, desta forma, é válido o princípio da superposição de efeitos, será efetuada a comparação apenas com a aplicação das ações devidas ao vento.

\section{METODOLOGIA}

Para fins de comparação entre o Método de Paredes Isoladas e o Método de Associação Plana de Painéis, foi elaborado um projeto de edifício em alvenaria estrutural, cujas características se encontram a seguir.

\subsection{Características do Projeto}

O projeto em estudo trata-se de um edifício localizado na cidade de Viçosa - Minas Gerais, em alvenaria estrutural com seis pavimentos-tipo, com dois apartamentos por andar. Na Figura 2 e na Figura 3 são apresentados respectivamente a planta-baixa do pavimento tipo e um corte transversal do edifício. Na Figura 4, apresenta-se a primeira fiada da alvenaria estrutural.

Foi utilizado no projeto o bloco da família M15 com módulo longitudinal de $15 \mathrm{~cm}$ e resistência característica de $6 \mathrm{MPa}$, obtida segundo [2].

\subsection{Obtenção das ações horizontais devidas ao vento}

As ações aplicadas na estrutura devidas ao vento foram obtidas com base em [1] e são aplicadas ao nível das lajes dos pavimentos. Para a cidade de Viçosa - Minas Gerais, obtém-se das isopletas da referida norma um valor de velocidade básica do vento igual a 32,5 m/s. A implantação do edifício se dará em um local fracamente acidentado (fator topográfico $s_{1}=1,0$ ) e terá função residencial (fator estatístico $s_{3}=1,0$ ). O coeficiente de arrasto na direção considerada, para o vento de baixa turbulência, obtido a partir da geometria da edificação é $C_{a}=1,3$.

Para a determinação do fator de rugosidade $s_{2}$, considerou-se o terreno com rugosidade na Categoria IV e as dimensões da edificação na Classe B da supracitada norma.

Na Tabela 1 são apresentadas as cotas de aplicação das ações horizontais (z), e, para cada cota, os valores de: fator de rugosidade $\left(s_{2}\right)$, velocidade característica do vento $\left(v_{k}\right)$, pressão dinâmica $(q)$, área de influência das ações $(A)$ e as forças devidas ao vento $(F)$.

Tabela 1. Variáveis utilizadas na determinação das forças devidas ao vento na estrutura

\begin{tabular}{cccccc}
\hline $\mathbf{z}(\mathrm{m})$ & $\boldsymbol{s}_{\boldsymbol{2}}$ & $\boldsymbol{v}_{\boldsymbol{k}}(\mathrm{m} / \mathrm{s})$ & $\boldsymbol{q}\left(\mathrm{kN} / \mathrm{m}^{2}\right)$ & $\boldsymbol{A}\left(\mathrm{m}^{2}\right)$ & $\boldsymbol{F}(\mathrm{kN})$ \\
\hline 2,90 & 0,76 & 24,70 & 0,3740 & 56,55 & 27,92 \\
5,80 & 0,77 & 25,03 & 0,3839 & 56,55 & 28,66 \\
8,70 & 0,81 & 26,33 & 0,4248 & 56,55 & 31,71 \\
11,60 & 0,85 & 27,63 & 0,4678 & 56,55 & 34,92 \\
14,50 & 0,88 & 28,60 & 0,5014 & 56,55 & 37,43 \\
17,40 & 0,89 & 28,93 & 0,5129 & 65,03 & 44,02 \\
\hline
\end{tabular}




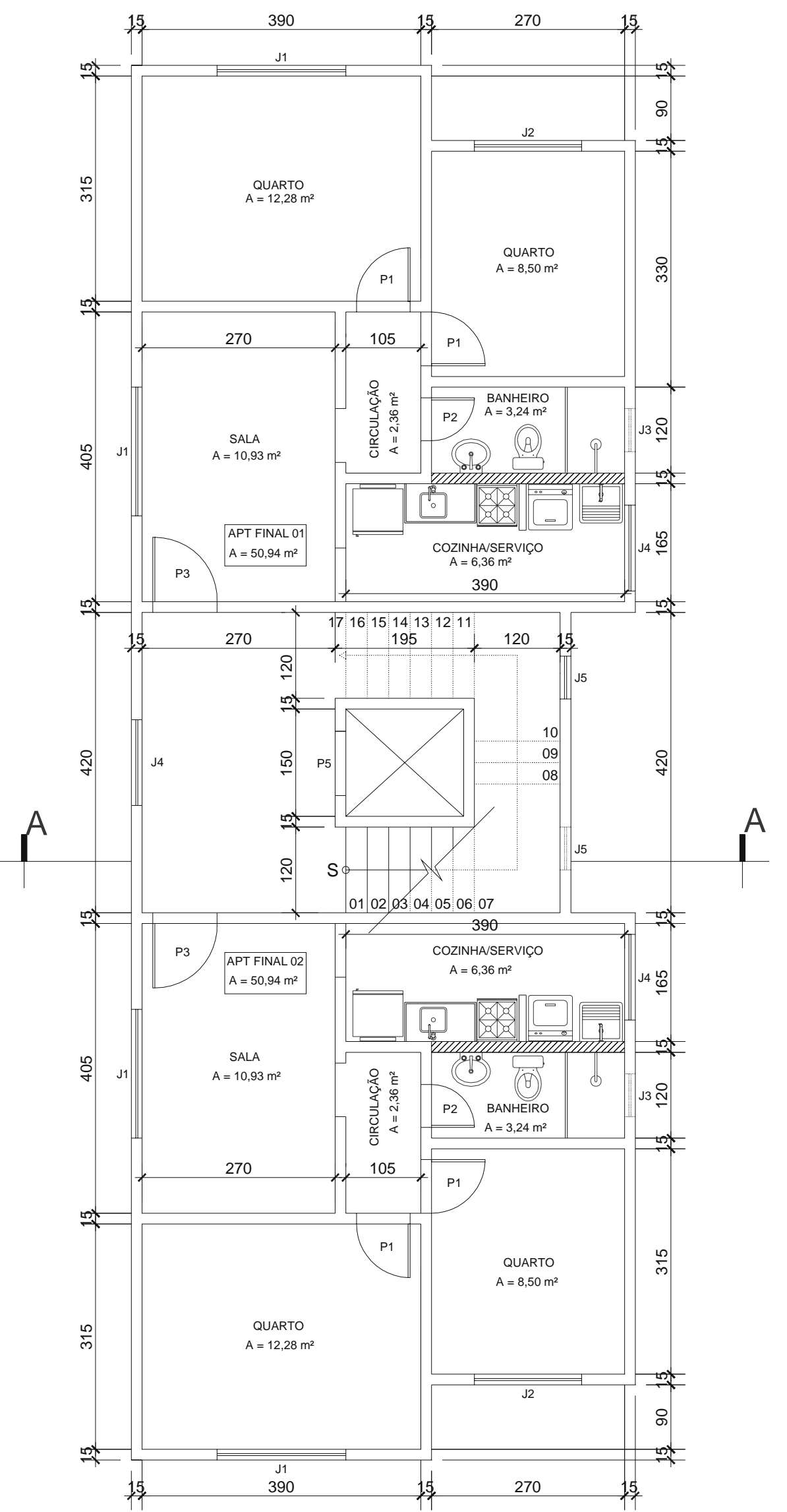

Figura 2. Planta-baixa do pavimento-tipo. 


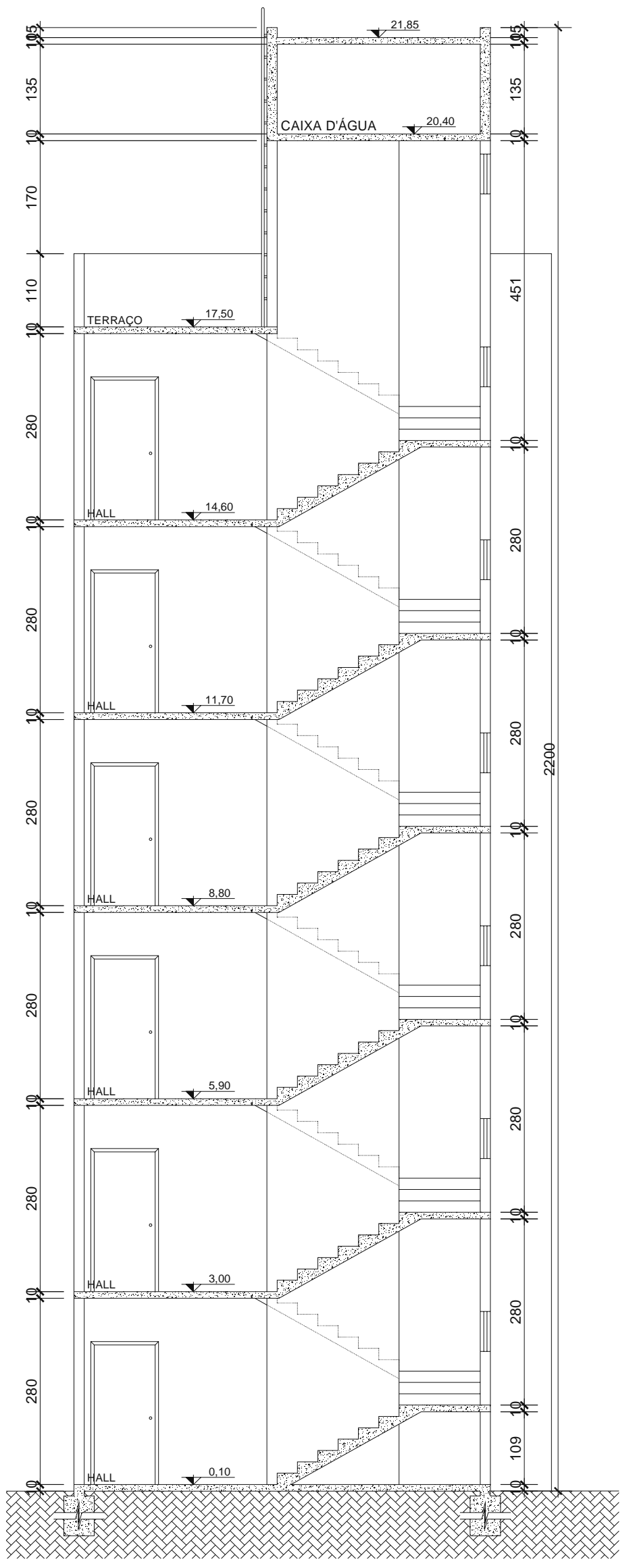

Figura 3. Corte transversal A-A. 


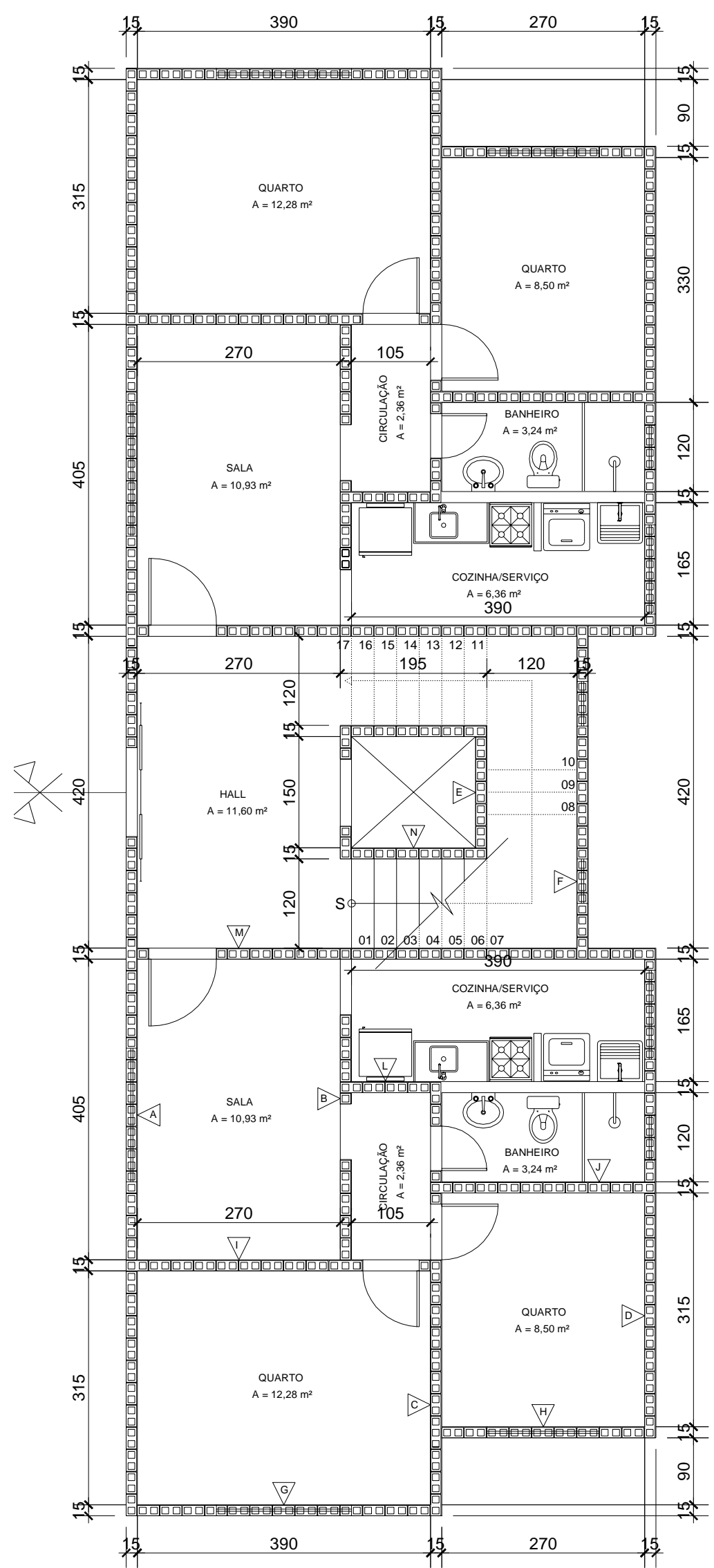

Figura 4. Primeira fiada de alvenaria. 


\section{RESULTADOS E DISCUSSÃO}

\subsection{Distribuição das ações horizontais: Método de Paredes Isoladas}

Para efeito da absorção dos esforços produzidos pelas ações horizontais atuantes na direção da simetria do edifício, são considerados os painéis de contraventamento compostos pelas paredes paralelas às ações acrescidas das eventuais abas, que são trechos de paredes na direção perpendicular à do vento, porém amarrados às paredes de contraventamento. Estas abas podem ter comprimento máximo de seis vezes a espessura das paredes, como mostrado na Figura 5 ([2] e [4]).

Na Tabela 2, apresentam-se as rigidezes relativas dos painéis, calculadas conforme apresentado no item 1.2, e na Tabela 3 são apresentadas as forças de vento atuantes em cada uma das paredes.

Com os valores das ações do vento aplicadas em cada pavimento dos oito painéis de contraventamento, podem-se obter os momentos fletores máximos em cada painel considerando-o como uma viga engastada e livre. Na Tabela 4 e na Tabela 5 são apresentados respectivamente os valores máximos dos momentos fletores e esforços cortantes para cada painel de contraventamento. $\mathrm{O}$ valor máximo de deslocamento lateral médio foi de $0,51 \mathrm{~cm}$.
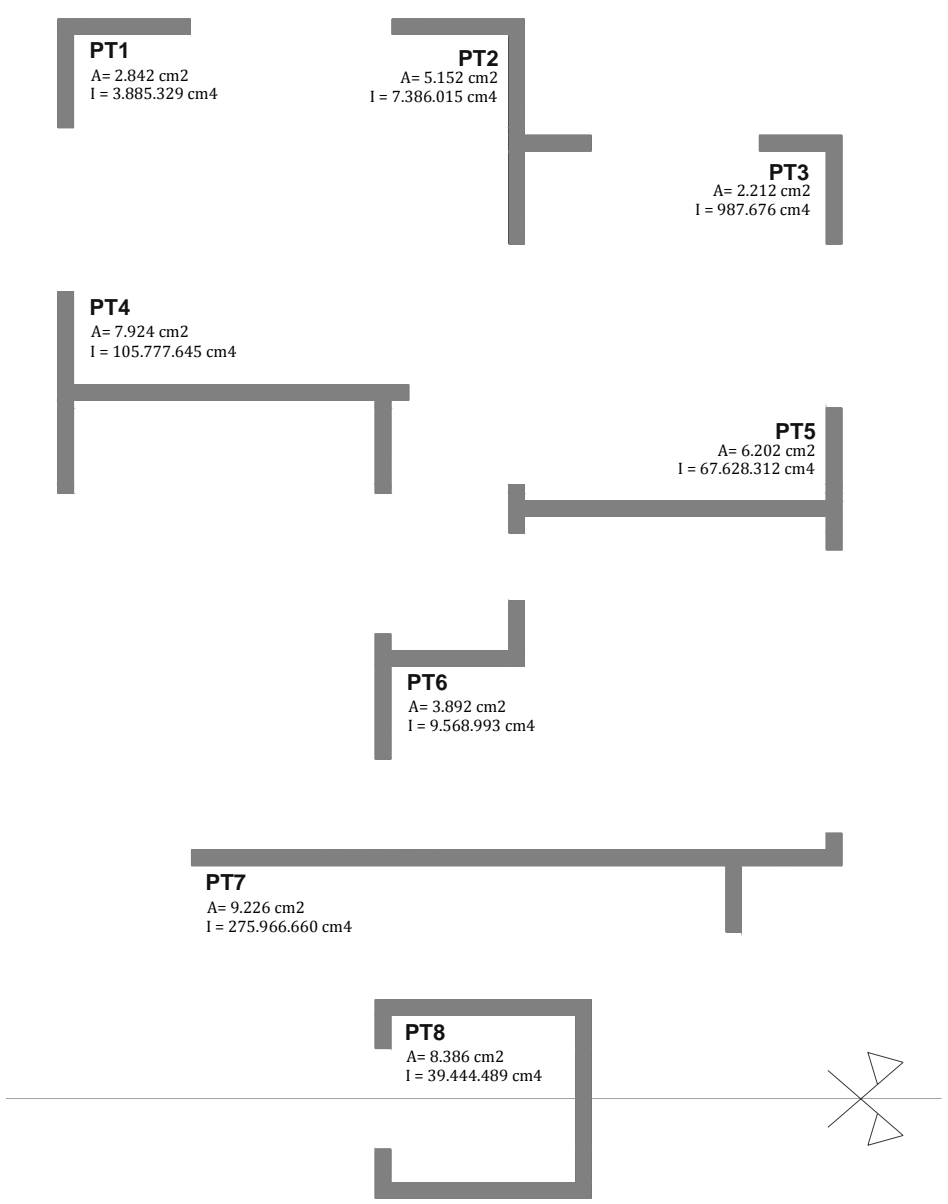

Figura 5. Painéis de contraventamento - Método de Paredes Isoladas. 
Tabela 2. Rigidezes relativas dos painéis de contraventamento.

\begin{tabular}{|c|c|c|c|}
\hline Painel & Quant. & $I_{i}$ & $R_{i}$ \\
\hline PT1 & 2 & 3.885 .329 & 0,004 \\
\hline РT2 & 2 & 7.386 .015 & 0,008 \\
\hline РT3 & 2 & 987.676 & 0,001 \\
\hline PT4 & 2 & 105.777 .645 & 0,108 \\
\hline PT5 & 2 & 67.628.312 & 0,069 \\
\hline PT6 & 2 & 9.568 .993 & 0,010 \\
\hline PT7 & 2 & 275.966 .660 & 0,281 \\
\hline \multirow[t]{2}{*}{ PT8 } & 1 & 39.444 .489 & 0,040 \\
\hline & & 981.845 .750 & \\
\hline
\end{tabular}

Tabela 3. Forças devidas ao vento aplicadas em cada parede.

\begin{tabular}{c|cccccccc}
\hline \multirow{2}{*}{ Pav. } & \multicolumn{7}{|c}{ Forças de Vento (kN) } \\
\cline { 2 - 9 } & PT1 & PT2 & PT3 & PT4 & PT5 & PT6 & PT7 & PT8 \\
\hline 6 & 0,17 & 0,33 & 0,04 & 4,74 & 3,03 & 0,43 & 12,37 & 1,77 \\
5 & 0,15 & 0,28 & 0,04 & 4,03 & 2,58 & 0,36 & 10,52 & 1,50 \\
4 & 0,14 & 0,26 & 0,04 & 3,76 & 2,41 & 0,34 & 9,81 & 1,40 \\
3 & 0,13 & 0,24 & 0,03 & 3,42 & 2,18 & 0,31 & 8,91 & 1,27 \\
2 & 0,11 & 0,22 & 0,03 & 3,09 & 1,97 & 0,28 & 8,05 & 1,15 \\
1 & 0,11 & 0,21 & 0,03 & 3,01 & 1,92 & 0,27 & 7,85 & 1,12 \\
\hline
\end{tabular}

Tabela 4. Momentos fletores máximos nos painéis de contraventamento pelo procedimento do Método de Paredes Isoladas.

\begin{tabular}{c|cccccccc}
\hline \multirow{2}{*}{ Pav. } & \multicolumn{7}{|c}{ Momento fletor máximo $(\mathbf{k N m})$} \\
\cline { 2 - 9 } & PT1 & PT2 & PT3 & PT4 & PT5 & PT6 & PT7 & PT8 \\
\hline 1 & 8,85 & 16,83 & 2,25 & 240,98 & 154,07 & 21,80 & 628,69 & 89,86 \\
\hline
\end{tabular}

Tabela 5. Esforços cortantes máximos nos painéis de contraventamento contraventamento pelo procedimento do Método de Paredes Isoladas.

\begin{tabular}{c|cccccccc}
\hline \multirow{2}{*}{ Pav. } & \multicolumn{7}{|c}{ Esforço cortante máximo (kN) } \\
\cline { 2 - 9 } & PT1 & PT2 & PT3 & PT4 & PT5 & PT6 & PT7 & PT8 \\
\hline 1 & 0,81 & 1,54 & 0,21 & 22,05 & 14,10 & 1,99 & 57,52 & 8,22 \\
\hline
\end{tabular}

\subsection{Distribuição das ações horizontais: Método de Associação Plana de Painéis}

\subsubsection{Generalidades}

Para a obtenção dos esforços solicitantes na estrutura devidos ao vento pelo Método da Associação Plana de Painéis, modelou-se no software SAP 2000 os pórticos que representam a associação plana dos painéis, com aberturas e sem aberturas.

Como apresentado no item 1.3, foram encontradas na literatura duas recomendações distintas para consideração do comprimento dos trechos rígidos dos lintéis, quais sejam a recomendação de [5] e a recomendação de [3]. Neste trabalho, foram realizadas análises utilizando ambas as recomendações.

Os elementos biarticulados utilizados para simular a presença das lajes possuem largura igual a $200 \mathrm{~cm}$, altura igual a $10 \mathrm{~cm}$ e comprimento igual a $100 \mathrm{~cm}$ ([6]). 


\subsubsection{Consideração dos lintéis de acordo com [5]}

O modelo geométrico para análise do pórtico por associação plana de painéis e considerando o comprimento dos trechos dos lintéis de acordo com as recomendações de [5] é apresentado na Figura 6 e um esquema em planta de cada parede pode ser visto na Figura 4.

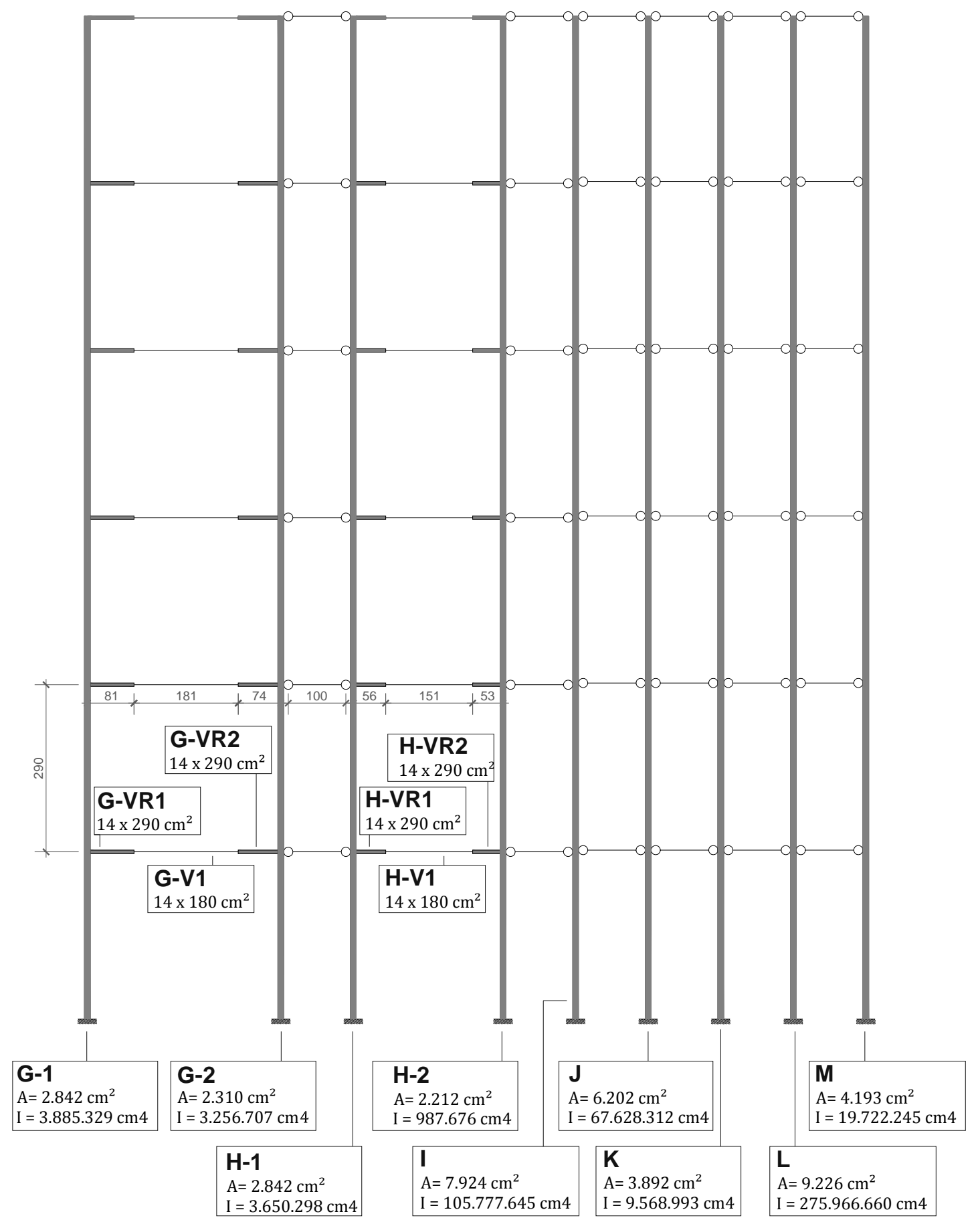

Figura 6. Pórtico formado pela associação plana de painéis (consideração dos lintéis conforme proposta de [5]). 
Os valores dos momentos fletores e esforços cortantes máximos na base de cada elemento vertical do pórtico, obtidos da análise realizada, são apresentados na Tabela 6 e na Tabela 7, respectivamente. O valor máximo de deslocamento lateral foi de $0,41 \mathrm{~cm}$.

Tabela 6. Momentos fletores máximos pelo método da Associação Plana de Painéis com consideração dos lintéis conforme [5].

\begin{tabular}{c|ccccccccc}
\hline \multirow{2}{*}{ Pav. } & \multicolumn{8}{|c}{ Momento fletor máximo (kNm) } \\
\cline { 2 - 10 } & G-1 & G-2 & H-1 & H-2 & I & J & K & L & M \\
\hline 1 & 15,77 & 12,18 & 4,88 & 3,95 & 192,97 & 133,30 & 22,98 & 462,58 & 44,55 \\
\hline
\end{tabular}

Tabela 7. Esforços cortantes máximos pelo método da Associação Plana de Painéis com consideração dos lintéis conforme [5].

\begin{tabular}{c|ccccccccc}
\hline \multirow{2}{*}{ Pav. } & \multicolumn{10}{|c}{ Esforço cortante máximo (kN) } \\
\cline { 2 - 10 } & G-1 & G-2 & H-1 & H-2 & I & J & K & L & M \\
\hline 1 & 6,91 & 5,27 & 2,46 & 1,94 & 19,69 & 15,59 & 3,84 & 39,96 & 6,67 \\
\hline
\end{tabular}

Para os lintéis, o valor de esforço cortante máximo obtido na análise foi de 8,82 kN.

\subsubsection{Consideração dos lintéis de acordo com o [3]}

O modelo geométrico para a análise do pórtico com a associação plana de painéis, considerando o comprimento dos trechos dos lintéis de acordo com as recomendações de [3] é apresentado na Figura 7. O esquema em planta de cada parede pode ser visto na Figura 4.

Os valores dos momentos máximos e esforços cortantes máximos na base de cada elemento vertical do pórtico, obtidos da análise realizada, são apresentados na Tabela 8 e na Tabela 9, respectivamente. O valor máximo de deslocamento lateral foi de $0,41 \mathrm{~cm}$.

Tabela 8. Momentos fletores máximos pelo método da Associação Plana de Painéis com consideração dos lintéis conforme [3].

\begin{tabular}{c|ccccccccc}
\hline \multirow{2}{*}{ Pav. } & \multicolumn{8}{|c}{ Momento fletor máximo (kNm) } \\
\cline { 2 - 10 } & G-1 & G-2 & H-1 & H-2 & I & J & K & L & M \\
\hline 1 & 16,06 & 12,18 & 4,90 & 3,92 & 195,73 & 135,18 & 23,28 & 469,54 & 45,16 \\
\hline
\end{tabular}

Tabela 9. Esforços cortantes máximos pelo método da Associação Plana de Painéis com consideração dos lintéis conforme [3].

\begin{tabular}{c|ccccccccc}
\hline \multirow{2}{*}{ Pav. } & \multicolumn{10}{|c}{ Esforço cortante máximo (kN) } \\
\cline { 2 - 10 } & G-1 & G-2 & H-1 & H-2 & I & J & K & L & M \\
\hline 1 & 6,67 & 4,98 & 2,41 & 1,87 & 19,79 & 15,68 & 3,86 & 40,34 & 6,72 \\
\hline
\end{tabular}

Para os lintéis, o valor de esforço cortante máximo obtido na análise foi de 7,88kN. 


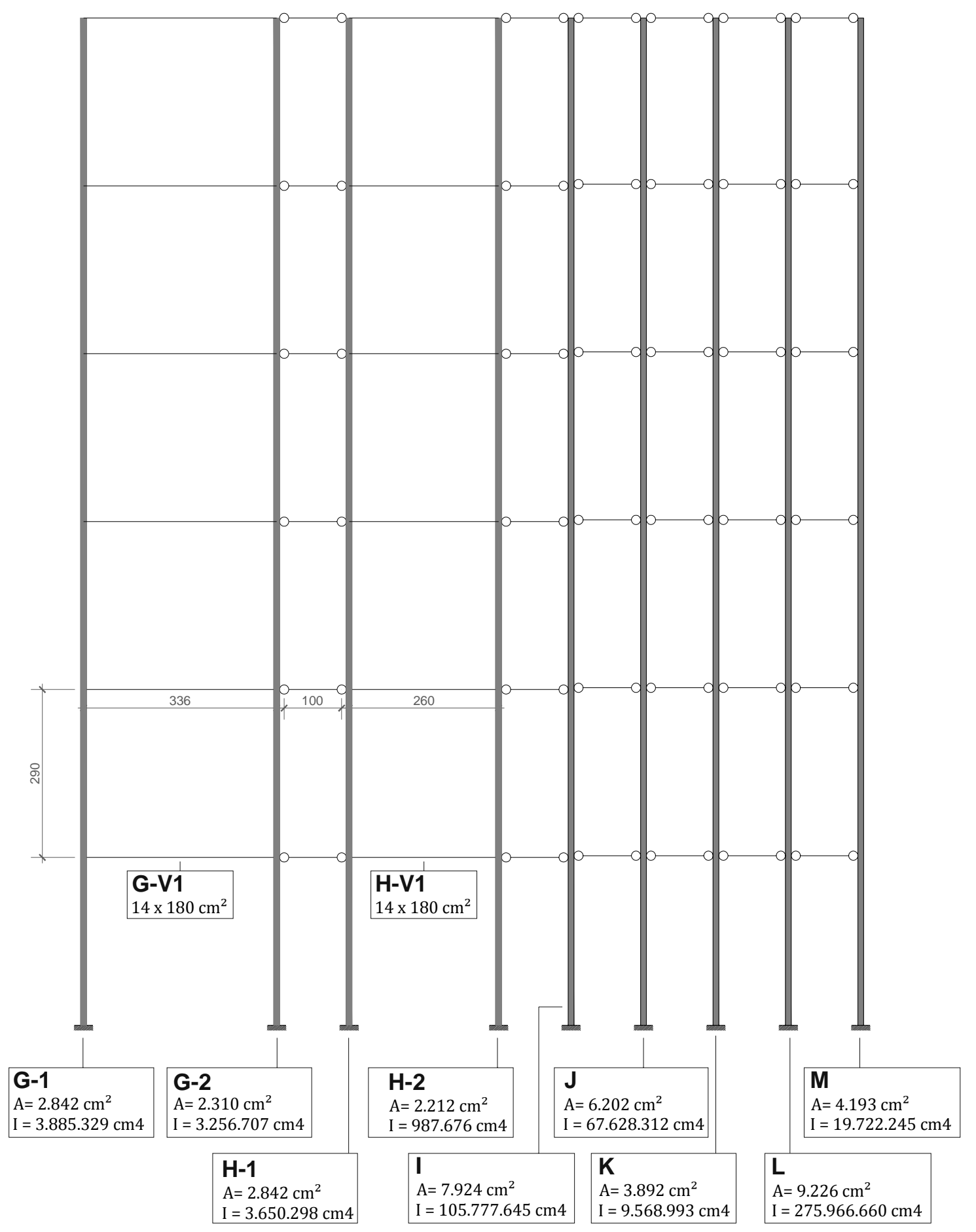

Figura 7. Pórtico formado por associação plana de painéis (consideração dos lintéis conforme proposta de [3]). 


\subsection{Discussão dos resultados}

Neste item são apresentadas as comparações entre os métodos de distribuição de ações horizontais, em termos de esforços solicitantes no primeiro pavimento e em termos de deslocamentos médios no último pavimento.

Para o entendimento dos gráficos apresentados a seguir, no Quadro 1 é apresentada uma legenda para simbologia utilizada e na Tabela 10 é apresentada a correspondência entre os painéis de contraventamento pelo Método de Paredes Isoladas e pelo Método de Associação Plana de Painéis.

Quadro 1. Legenda para os gráficos seguintes.

MPI Método de paredes isoladas

MAPP-R Método de associação plana de painéis: consideração dos lintéis de acordo com [5]

MAPP-E Método de associação plana de painéis: consideração dos lintéis de acordo com [3]

Tabela 10. Correspondência entre os painéis utilizados no Método de Paredes Isoladas e no Método de Associação Plana de Painéis.

\begin{tabular}{ccc}
\hline $\begin{array}{c}\text { Nomenclatura utilizada nos } \\
\text { gráficos desta seção }\end{array}$ & $\begin{array}{c}\text { Método de Paredes } \\
\text { Isoladas }\end{array}$ & $\begin{array}{c}\text { Método de Associação } \\
\text { Plana de Painéis }\end{array}$ \\
\hline 1 & PT1 & $\mathrm{G}-1$ \\
2 & PT2 & $\mathrm{G}-2+\mathrm{H}-1$ \\
3 & PT3 & $\mathrm{H}-2$ \\
4 & PT4 & $\mathrm{I}$ \\
5 & PT5 & $\mathrm{J}$ \\
6 & PT6 & $\mathrm{K}$ \\
7 & PT7 & $\mathrm{L}$ \\
8 & PT8 & $2 \times \mathrm{M}$ \\
\hline
\end{tabular}

Na Figura 8 são comparados os momentos fletores na base do primeiro pavimento, obtidos nas análises realizadas. Nota-se que para o painel mais solicitado, que neste caso é o determinante para o dimensionamento do pavimento, o momento fletor obtido quando se utiliza o MAPP-R ou o MAPP-E é inferior ao obtido pelo MPI em 26\% e 25\%, respectivamente. Observa-se também que nos painéis submetidos a menores solicitações, os esforços são maiores quando se considera a associação plana dos painéis, demonstrando uma melhor distribuição dos esforços nos painéis. A pequena diferença entre o MAPP-R e o MAPP-E se deve ao fato de os lintéis serem considerados ligeiramente mais rígidos no primeiro, tendo em vista a redução em seu comprimento.

Na Figura 9 é feita a comparação entre os métodos de distribuição das ações horizontais em termos de força cortante na base do primeiro pavimento. Observa-se que no Método da Associação Plana de Painéis ocorre uma interação entre os painéis de forma que a distribuição dos esforços torna-se mais homogênea que no Método de Paredes Isoladas. Em 
painéis submetidos a pequenos esforços, a força cortante obtida pelo Método da Associação Plana de Painéis foi de até nove vezes maior que no Método de Paredes Isoladas. Por outro lado, no painel que determina o dimensionamento, a força cortante obtida pelo MAPP-R e pelo MAPP-E foram respectivamente 31\% e 30\% abaixo daquela obtida pelo MPI.

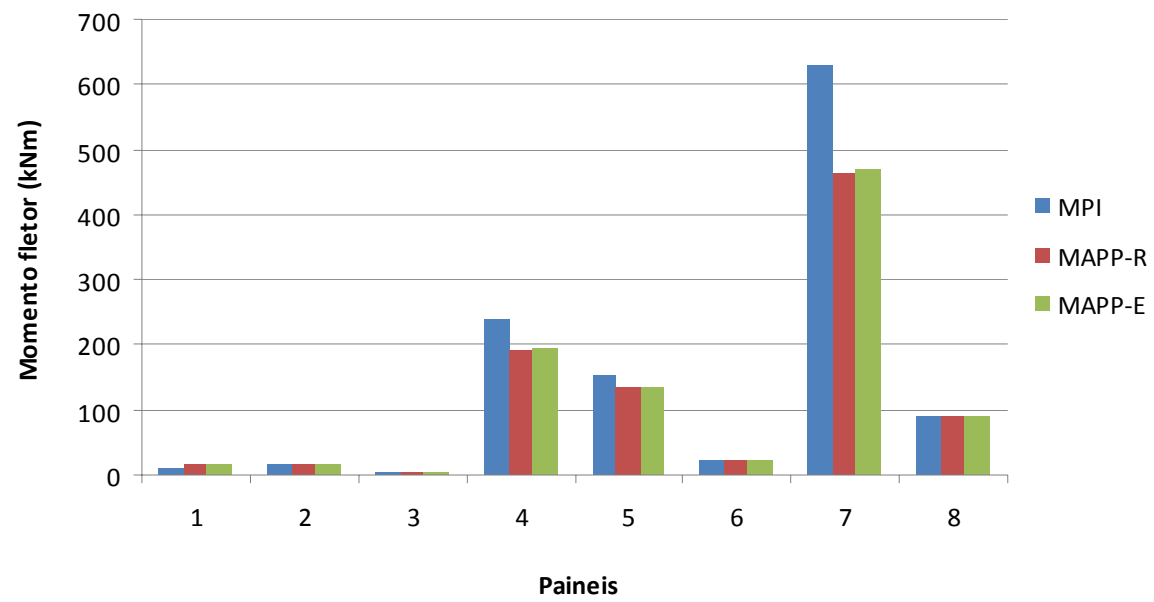

Figura 8. Comparação entre os métodos de distribuição de ações horizontais - momentos fletores na base do primeiro pavimento.

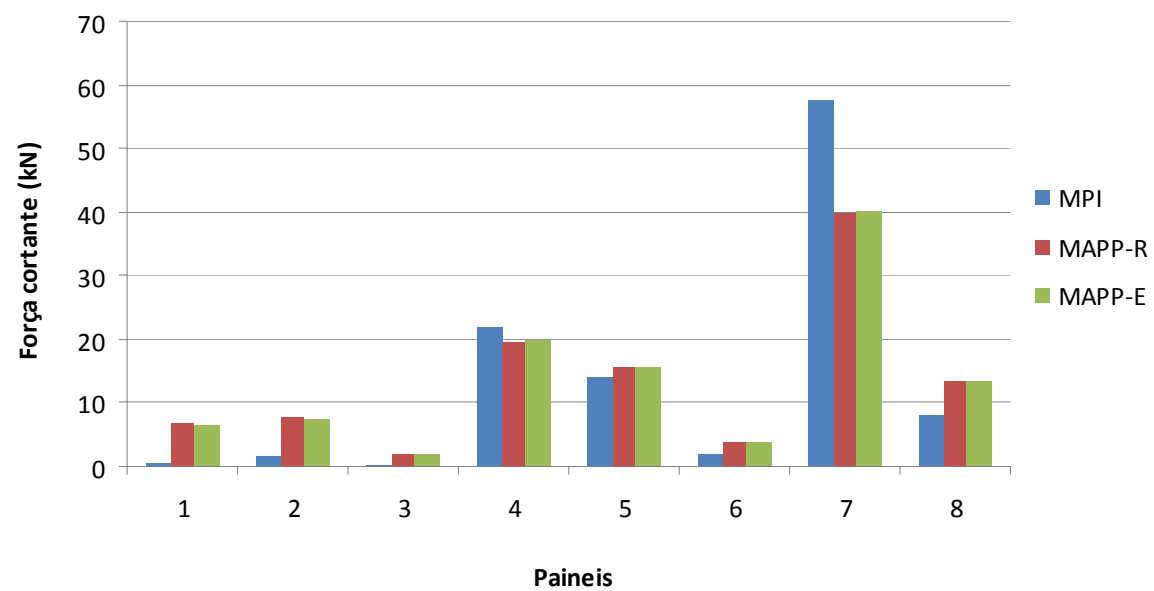

Figura 9. Comparação entre os métodos de distribuição de ações horizontais - força cortante na base do primeiro pavimento.

Em termos de deslocamentos horizontais médios do topo do edifício, os valores obtidos pelo Método da Associação Plana de Painéis também são menores que aqueles obtidos pelo Método de Paredes Isoladas. Na Figura 10 apresentam-se os valores de deslocamentos no topo do último pavimento. Nota-se uma redução de $26 \%$ no cálculo dos deslocamentos quando se utiliza o Método da Associação Plana de Painéis, em relação ao Método de Paredes Isoladas. Quando se comparam o MAPP-R e o MAPP-E, os resultados são praticamente iguais. 


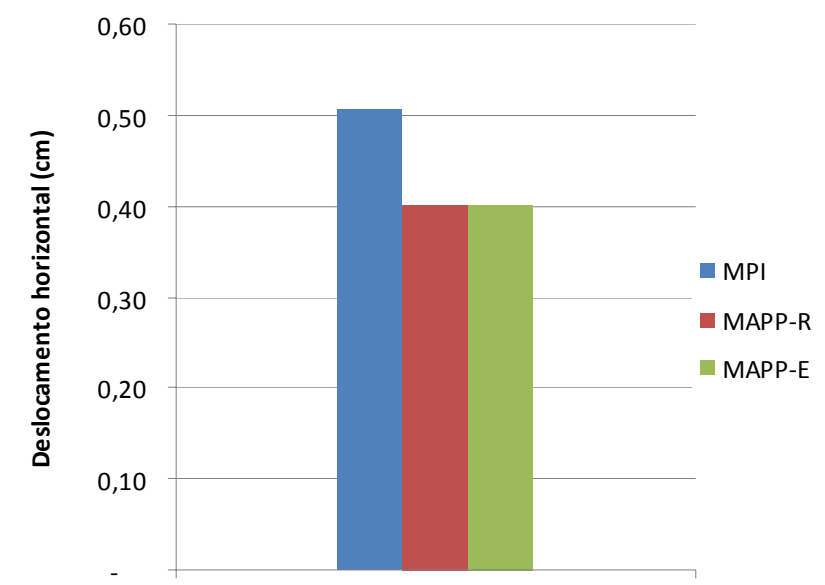

Figura 10. Comparação entre os métodos de distribuição de ações horizontais deslocamentos médios no último pavimento.

Na Figura 11 é apresentada uma comparação de força cortante nos lintéis, obtidas pelas duas formas apresentadas de consideração dos mesmos. A força cortante pelo MAPP-R é superior à obtida pelo MAPP-E em 12\%.

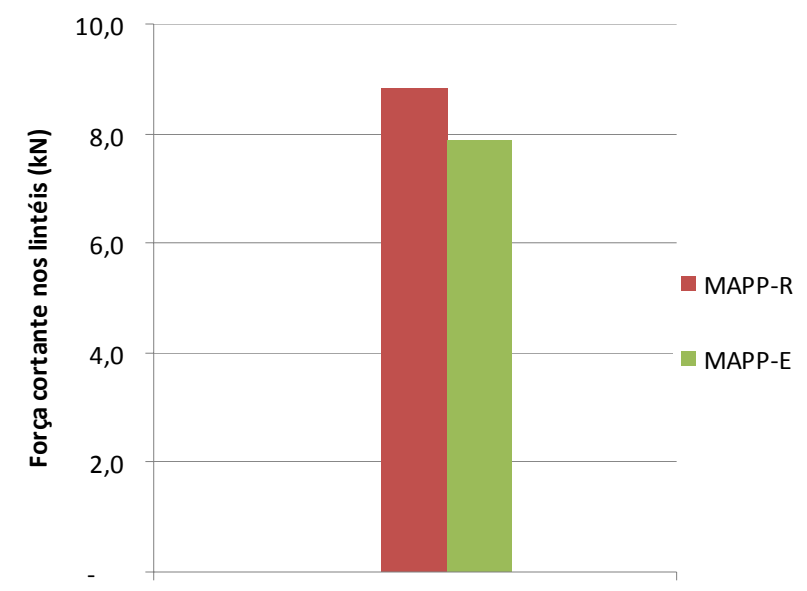

Figura 11. Força cortante nos lintéis pelo Método da Associação Plana de Painéis consideração dos lintéis conforme [5] e [3]

Para o Método da Associação Plana de Painéis, os esforços solicitantes e os deslocamentos obtidos são praticamente iguais para ambas as considerações de geometria dos lintéis. Já os esforços solicitantes nos lintéis são maiores quando se considera a recomendação de [5], uma vez que, neste caso, o comprimento rígido dos lintéis é maior que o da recomendação de [3]. 


\section{CONCLUSÃO}

Neste trabalho foram realizadas comparações entre dois métodos de distribuição de ações horizontais em edifícios de alvenaria estrutural com pelo menos um eixo de simetria: o Método de Paredes Isoladas e o Método da Associação Plana de Painéis. O primeiro considera as paredes trabalhando isoladamente como vigas engastadas na base e livres na outra extremidade. O segundo considera que os painéis que absorvem as ações horizontais são associados em série e ligados por elementos que simulam a laje. Na literatura, observaram-se duas diferentes formas para consideração dos lintéis no Método da Associação Plana de Painéis, quais sejam:

- consideração dos lintéis de acordo com recomendação de [5];

- consideração dos lintéis de acordo com recomendação de [3].

As análises pelo Método da Associação Plana de Painéis foram realizadas no software SAP 2000, considerando-se o comportamento linear dos materiais.

O Método de Paredes Isoladas é um procedimento de distribuição de ações horizontais simples, eficiente e que conduz a resultados seguros, para o caso de estruturas de contraventamentos simétricos.

O Método da Associação Plana de Painéis requer a utilização de um software para análise da estrutura e é importante salientar que, para que este método funcione de forma satisfatória, os elementos que simulam a existência da laje devem apresentar uma geometria adequada. Ou seja, estes elementos devem ser suficientemente rígidos para que os deslocamentos de todos os nós de um mesmo nível sejam iguais. No entanto, essa rigidez não pode ser muito grande, para que não ocorra um mau condicionamento numérico da matriz de rigidez global da estrutura, o que inviabilizaria a obtenção de resultados coerentes.

A partir dos resultados apresentados, pode-se concluir que o Método da Associação Plana de Painéis conduz a esforços solicitantes mais homogêneos do que o Método de Paredes Isoladas. Deste modo, os esforços solicitantes e os deslocamentos dos painéis que determinam o dimensionamento da estrutura são menores quando se utiliza o Método da Associação Plana de Painéis, tornando este método mais econômico que o Método de Paredes Isoladas.

Também foram realizadas comparações entre as duas formas de consideração dos lintéis no Método da Associação Plana de Painéis. Os resultados mostraram que as diferenças são muito pequenas, tanto em termos de esforços solicitantes nos painéis quanto de deslocamentos. É importante observar que os lintéis foram verificados à flexão e ao cisalhamento. Estas verificações são importantes para garantir o comportamento estrutural segundo o modelo idealizado.

\section{Agradecimentos}

Os autores agradecem à FAPEMIG e ao Departamento de Engenharia Civil da Universidade Federal de Viçosa pelo apoio para a realização deste trabalho. 


\section{REFERÊNCIAS}

[1] Associação Brasileira de Normas Técnicas. NBR 6123: Forças devidas ao vento em edificações. Rio de Janeiro, 1988.

[2] Associação Brasileira de Normas Técnicas. NBR 15961-1: Alvenaria estrutural - Blocos de concreto - Parte 1: Projeto. Rio de Janeiro, 2011.

[3] European Committee Standardization. Eurocode 6 - Design of masonry structures. Part 1. London, BSI, 1996

[4] Parsekian G. A., Soares M. M., Alvenaria estrutural em blocos cerâmicos: projeto, execução e controle. O Nome da Rosa, São Paulo, 2010.

[5] Ramalho M. A., Corrêa M. R. S., Projeto de edifícios de alvenaria estrutural. PINI, São Paulo, 2003.

[6] Rodrigues C. H., Jacintho A. E. P. G. A., Carnio, M. A., Pimentel L. L., “Avaliação da estabilidade global do Edifício Norte Sul em Campinas”. Concreto e Construções, n. 62, 7685, 2011. 